\title{
HUBUNGAN ANTARA WORK FAMILY CONFLICT DENGAN KUALITAS KEHIDUPAN KERJA PADA KARYAWATI YANG TELAH MENIKAH DI PT. K
}

\author{
Rika Cristy $^{1}$ \& Devi Jatmika ${ }^{2}$ \\ ${ }^{12}$ Program Studi Psikologi Universitas Bunda Mulia \\ dephey@gmail.com
}

\begin{abstract}
Along with the increasing advanced economy in this era, it's a common thing to see woman pursue her career by working in the company. Married women and working in company often experienced a work family conflict. The aim of this study is to analyze the correlation of work family conflict with quality of work life. This study was conducted using a quantitative approach with correlational type. Subject of this study were 116 female employees who had been married, has a children, and also a permanent employees in PT.K. The data are collected by instrument which made by researcher. Using pearson correlation method, result of this study found significant negative correlation between work family conflict and quality of work life. Company is expected to improve the quality of work life in order to help female worker to balance her role so that company can have a good human resources and achive company goals.
\end{abstract}

Keywords: Work family conflict, quality of work-life, married employee

\begin{abstract}
ABSTRAK
Seiring dengan perkembangan ekonomi yang semakin maju di era globalisasi ini, sudah tidak asing bagi masyarakat melihat wanita yang meniti karirnya dalam perusahaan. Wanita yang telah menikah dan juga meniti karirnya seringkali mengalami work family conflict. work family conflict yang tinggi dialami oleh karyawati yang bekerja di PT.K. Melihat adanya fenomena work family conflict yang dialami oleh karyawati di PT.K, peneliti tertarik untuk melihat kaitannya dengan kualitas kehidupan kerja yang dimiliki oleh karyawati di PT.K. Penelitian ini dilakukan dengan menggunakan pendekatan kuantitatif dengan jenis penelitian korelasional. Subjek dari penelitian ini adalah 116 orang karyawati yang telah menikah, memiliki anak, dan juga merupakan karyawan tetap PT.K. Data diperoleh melalui instrumen penelitian yang disusun sendiri oleh peneliti. Untuk melihat apakah terdapat hubungan antara work family conflict dengan kualitas kehidupan kerja peneliti menggunakan korelasi pearson. Hasil dari penelitian ini adalah terdapat hubungan negatif signifikan yang cukup kuat antara work family conflict dengan kualitas kehidupan kerja. Perusahaan diharapkan dapat meningkatkan kualitas kehidupan kerja pada perusahaan agar dapat membantu karyawati untuk dapat menyeimbangkan perannya, sehingga perusahaan dapat memiliki sumber daya yang baik dan dapat mencapai tujuan perusahaan.
\end{abstract}

Kata kunci: Konflik kerja keluarga, kualitas kehidupan keja, karyawati yang telah menikah 


\section{PENDAHULUAN}

Seiring dengan perkembangan ekonomi yang semakin maju di era globalisasi ini, sudah tidak asing bagi masyarakat melihat wanita yang meniti karirnya dalam perusahaan. Peran wanita di masa sekarang sudah tidak lagi di kaitkan hanya dengan kodratnya sebagai seorang istri yang hanya mengerjakan urusan rumah tangga saja, namun banyak juga wanita yang berperan sebagai ibu rumah tangga sekaligus meniti karirnya di perusahaan. Di Indonesia, peran perempuan di tempat kerja termasuk yang cukup dominan dibanding di negara-negara lain, terbukti dari banyaknya jumlah karyawati perempuan. Menurut data BPS (2018) Tingkat Partisipasi Angkatan Kerja perempuan sebesar 51.88\%, yang mana meningkat sebesar 0.99\% dibadingkan tahun sebelumnya. Berdasarkan data diatas dapat dilihat bahwa hal tersebut membuktikan sudah cukup banyak wanita yang bekerja di Indonesia. Menurut Chusniatun, Kuswardhani dan Suwandi (2014), dalam urusan karir, wanita mendasari diri mereka dengan pertimbangan - pertimbangan yang berhubungan dengan kodratnya sebagai wanita dan juga keluarga. Hal ini akan berpengaruh apabila wanita tersebut sudah menikah dan memiliki anak karena pekerjaannya dapat memicu timbulnya dilema peran antara pekerjaan dan keluarganya (Chusniatun, Kuswardhani dan Suwandi 2014).

Menurut penelitian Apperson (dalam Buhali, 2007), mayoritas pria dan wanita sekarang ini mempunyai kedudukan ganda, sebagai orangtua dan juga karyawati dengan jenis pekerjaan full-time. Kondisi ini menyebabkan sebagian besar waktu seorang pekerja itu dihabiskan di tempat kerja. Hal tersebut tentu dapat menjadi suatu masalah bagi individu yang sudah menikah dan masih bekerja di sebuah perusahaan dimana seringkali individu mengalami kesulitan dalam menyeimbangkan peran gandanya sebagai istri ataupun suami juga, hal ini seringkali disebut Work family conflict.

Work family conflict merupakan suatu konflik yang mengacu pada sejauh mana hubungan antara pekerjaan dan keluarga saling terganggu (Greenhaus dalam Murharnis, Etikaerina, \& Yulianto, 
2011). Konflik ini terjadi karena tuntutan peran yang berasal dari satu domain yang berasal dari pekerjaan atau keluarga yang tidak sesuai dengan tuntutan peran yang berasal dari domain yang lain (Amin,2013). Pada dasarnya, hubungan antara pekerjaan dan keluarga merupakan hal yang kompleks dan dinamis. Maka, tidaklah mengherankan jika konflik antara pekerjaan dan keluarga adalah salah satu isu yang dirasa paling menekan yang dihadapi keluarga (Hattery dalam Murharnis, Etikaerina, \& Yulianto,2011)

Work family conflict yang terjadi dalam kehidupan individu memiliki dampak yang cukup berarti, karena setelah pekerjaan yang melelahkan setiap harinya, individu masih harus menjalankan perannya sebagai istri dirumah. Selain itu, disebutkan bahwa perbedaan gender juga merupakan hal yang berpengaruh terhadap kemunculan konflik keluarga. Hal ini didukung oleh pernyataan Fuchs (dalam Murharnis, Etikaerina, \& Yulianto, 2011) bahwa wanita yang mempunyai anak (ibu) cenderung berada di bawah tekanan yang lebih besar, terlebih lagi jika harus bekerja. Mengingat bahwa mengasuh anak biasanya dilakukan oleh wanita, maka keberadaan istri yang bekerja dapat lebih memicu terjadinya konflik keluarga (Adekola, 2010). Penelitian-penelitian sebelumnya telah menunjukkan bahwa Work family conflict seringkali dihubungkan dengan ketidakpuasan dan kesulitan individu untuk dapat menyeimbangkan peran dalam pekerjaan maupun dalam keluarga. (Greenhaus dalam Murharnis, Etikaerina, \& Yulianto,2011). Oleh karenanya, perusahaan selayaknya dapat menyediakan fasilitas bagi karyawati dalam rangka untuk dapat membantu para karyawati untuk dapat menyeimbangkan perannya di kedua domain tersebut.

Irawati (2015) menyatakan bahwa suasana kerja yang baik dapat menciptakan kualitas kehidupan kerja yang kondusif dalam rangka tercapainya tujuan organisasi, kondisi ini didasarkan dengan kualitas kehidupan kerja seseorang erat hubungannya dengan perilaku manajemen perusahaan baik didalam maupun diluar perusahaan. Kualitas kehidupan kerja merupakan suatu 
aspek penting bagi perusahaan agar dapat memiliki sumber daya manusia yang berkualitas guna mencapai tujuan organisasi (Irawati,2015). Perkembangan industri yang sedang sangat berkembang saat ini di Indonesia salah satunya bergerak pada bidang properti. Salah satu perusahaan properti yang sedang berkembang adalah PT.K. PT.K merupakan salah satu pengembang properti terkemuka di Indonesia yang mengkhususkan diri pada pertengahan pengembangan properti high-end yang didirikan pada tanggal 25 Maret 1981. Contoh proyek yang telah dikembangkan oleh PT.K adalah seperti Melati Mas Residence, Serpong Park, bangunan-bangunan bertingkat seperti Westmark, dan sebagainya. Saat ini PT.K memiliki 19 cabang yang berlokasi Jakarta yang bergerak di bidang properti, timah dan batu bara, dan sebagainya.

Peneliti telah melakukan wawancara awal mengenai Work family conflict dan kualitas kehidupan kerja pada karyawati yang telah menikah di PT.K. Berkaitan dengan berbagai konflik yang terjadi dalam pekerjaan dan rumah tangga yang dialami oleh individu, penelitian ini bertujuan untuk mengetahui apakah terdapat hubungan antara Work family conflict dengan kualitas kehidupan kerja pada karyawati yang telah menikah di PT. K.

Menurut Greenhaus dan Beutell (dalam Tsai, 2008), konflik peran ganda merupakan konflik inter - role dimana terdapat tuntutan peran dari pekerjaan dan tuntutan peran dari keluarga yang bertentangan. Hubungan antara pekerjaan dan keluarga dikonseptualisasikan sebagai konstruk bidirectional dimana peran dalam pekerjaan mempengaruhi peran dalam keluarga (Gutck, Searle dan Klepa; dalam Tsai, 2008). Seseorang dapat dikatakan mengalami konflik peran ganda ketika orang tersebut mengalami suatu ketegangan dalam menjalani peran pekerjaan dan peran dalam keluarganya (Almasitoh, 2011). Greenhaus dan Beutell (dalam Laksmi \& Hadi, 2012) menggambarkan tiga tipe konflik yang berkaitan dengan dilema peran perempuan antara perannya di rumah sebagai ibu rumah tangga dan juga pekerjaannya, yaitu: 
1) Time-Based Conflict, yaitu konflik yang terjadi karena waktu yang digunakan untuk memenuhi peran lainnya, meliputi pembagian waktu, energi dan kesempatan antara peran pekerjaan dan rumah tangga. Dalam hal ini, menyusun jadwal merupakan hal yang sulit dan waktu terbatas saat tuntutan dan perilaku yang dibutuhkan untuk memerankan keduanya tidak sesuai, 2) Strain based conflict, yaitu mengacu kepada munculnya ketegangan atau keadaan emosional yang dihasilkan oleh salah satu peran membuat seseorang sulit untuk memenuhi tuntutan perannya yang lain. Ketegangan peran ini bisa menyebabkan stress, tekanan darah meningkat, kecemasan, keadaan emosional, dan sakit kepala, dan 3) Behavior based conflict, yaitu konflik yang muncul ketika pengharapan dari suatu prilaku yang berbeda dengan pengharapan dari perilaku peran lainnya. Ketidaksesuaian prilaku individu ketika bekerja dan ketika di rumah, yang disebabkan perbedaan aturan perilaku seorang wanita karir biasanya sulit menukar antara peran yang dia jalani dengan peran yang lain.

Lau dan Bruce (dalam Considine \& Callus, 2001) mendefinisikan kualitas kehidupan bekerja adalah dinamika multidimensional yang meliputi beberapa konsep seperti jaminan kerja, sistem penghargaan, pelatihan dan karir peluang kemajuan, dan keikutsertaan di dalam pengambilan keputusan. Berdasarkan aspek kualitas kehidupan kerja, Zin (2004) menyebutkan terdapat tujuh dimensi dari kualitas kehidupan kerja yaitu:

\section{Pertumbuhan dan Pengembangan}

Dimensi pertumbuhan dan pengembangan mencakup dalam peluang untuk pertumbuhan dan mendapatkan jaminan suatu pekerjaan dapat memberi sumbangan dalam menetapkan dan mengembangkan kapasitas individu.

2. Partisipasi 
Dimensi partisipasi mencakup karyawati perlu diikutsertakan dalam pengambilan keputusan dan pelaksanaan pekerjaan, sesuai dengan posisi, kewenangan dan jabatan masing-masing

\section{Lingkungan fisik}

Dimensi lingkungan fisik mencakup kondisi-kondisi kerja yang aman dan sehat Individu tidak ditempatkan kepada keadaan yang dapat membahayakan fisik dan kesehatan mereka, waktu kerja mereka juga sesuai dengan jadwal yang telah ditetapkan. Begitu juga umur adalah sesuai dengan tugas yang dipertanggungjawabkan kepada mereka.

\section{Atasan}

Dimensi atasan mencakup dalam atasan wajib untuk menghargai hak-hak karyawati Hak pribadi seorang individu harus dihormati, memberi dukungan kebebasan bersuara dan terwujudnya pelayanan yang adil.

\section{Gaji dan benefit}

Dalam dimensi gaji dan benefit mencakup kompensasi yang mencukupi dan adil gaji yang diterima individu dari kerjanya dapat memenuhi standar gaji yang diterima umum, cukup untuk membiayai suatu tingkat hidup yang layak dan mempunyai perbandingan yang sama dengan gaji yang diterima orang lain dalam posisi yang sama.

6. Relevansi sosial

Dimensi relevansi sosial mencakup dalam tanggung jawab sosial organisasi. Organisasi haruslah mementingkan pengguna dan masyarakat secara keseluruhan semasa menjalankan aktivitasnya. Organisasi yang mengabaikan peranan dan tanggung jawab sosialnya akan menyebabkan pekerja tidak menghargai pekerjaan mereka

7. Integrasi sosial 
Pada dimensi integrasi sosial, dalam pekerjaannya, individu tidak dilayani dengan sikap curiga, mengutamakan konsep egalitarianism, adanya mobilitas untuk bergerak ke atas, merasa bagian dari suatu tim, mendapat dukungan dari kelompok-kelompok primer dan terdapat rasa hubungan kemasyarakatan serta hubungan antara perseorangan.

\section{METODE PENELITIAN}

Penelitian ini menggunakan metode penelitian kuantitatif dengan jenis penelitian korelasional. Sampel penelitian ini adalah seluruh karyawati yang telah menikah dan memiliki anak di PT. K yang berjumlah 116 orang. Alat ukur Work family conflict dibuat berdasarkan teori Work family conflict yang dikemukakan oleh Greenhaus dan Beutell (dalam Siregar, 2011). Dalam penelitian ini, instrumen penelitian diuji reliabilitas serta validitasnya dengan menggunakan teknik Alpha Cronbach. Kemudian peneliti menggunakan uji persyaratan asumsi dengan menggunakan OneSample Kolmogrov Smirnov Test. Jika data yang diperoleh dari penelitian ini terdistribusi secara normal $(\mathrm{p}>0,05)$ maka untuk melihat apakah terdapat hubungan antara Work family conflict dan kualitas kehidupan kerja, peneliti menggunakan korelasi Pearson Product Moment. Pengkategorian norma dari variabel

Nilai koefisien reliabilitas alpha $(\alpha)$ skala Work family conflict sebesar 0.936 dengan jumlah pernyataan sebanyak 35 butir. Alat ukur kualitas kehidupan kerja dibuat berdasarkan tujuah dimensi dari kualitas kehidupan kerja yang dikemukakan oleh Zin (2004). Koefisien reliabilitas alpha $(\alpha)$ dari skala kualitas kehidupan kerja sebesar 0.945 dengan jumlah pernyataan sebanyak 30 butir.

\section{HASIL}


Hasil pengolahan data deskriptif dari variabel Work family conflict diperoleh $\mathrm{M}=87.68, \mathrm{SD}=$ 13.5 dan kualitas kehidupan kerja dengan nilai $\mathrm{M}=79.87$, SD- 11 . Gambaran Work family conflict yang dirasakan oleh karyawati tergolong dalam kategori tinggi, hal ini dibuktikan dengan total persentase dari Work family conflict cenderung tinggi yaitu 54,4\%. Pada dimensi time based conflict terlihat gambaran Work family conflict berada pada kategori cukup tinggi dengan total persentase 57,1\%. Konflik yang terjadi pada karyawati PT.K meliputi kesulitan untuk menyeimbangkan waktu antara pekerjaan dan kesulitan individu untuk bersosialisasi dengan masyarakat sekitar karena individu merasa terlalu sibuk dalam pekerjaannya, baik dalam perusahaan maupun rumah tangga. Pada dimensi strain based conflict terlihat gambaran Work family conflict berada pada kategori tinggi dengan total persentase $61,4 \%$. Konflik yang terjadi pada karyawati PT.K diantaranya adalah individu mengalami kesulitan untuk menyelesaikan pekerjaan rumahnya karena tuntutan pekerjaan di perusahaan yang terlalu padat, selain itu konflik lainnya adalah pihak kantor yang memberikan tanggapan buruk jika individu tidak dapat menyelesaikan pekerjaannya dengan baik. Pada dimensi behavior based conflict terlihat gambaran Work family conflict berada pada kategori cukup tinggi yaitu 50,9\%. Konflik yang terjadi pada karyawati di PT.K adalah mereka seringkali merasa lelah jika harus mengerjakan pekerjaan rumah atau sekedar bersantai dengan keluarga setelah rutinitas kantor yang dilakukan olehnya, individu merasa ingin langsung dapat beristirahat setelah pulang dari pekerjaannya.

Pada hasil penelitian diperoleh gambaran kualitas kehidupan kerja yang dirasakan oleh karyawati PT. K berada pada kategori cenderung tinggi dengan total persentase $57,9 \%$. Sementara itu, pada dimensi pertumbuhan dan pengembangan terlihat gambaran kualitas kehidupan kerja berada pada kategori tinggi dengan total persentase 72,8\%. Hal ini menunjukkan bahwa PT.K telah memberikan kesempatan pada para karyawatinya untuk mengembangkan keterampilannya, salah satu 
kekurangan pada PT.K berdasarkan hasil wawancara adalah PT.K seringkali mengadakan pelatihan namun jarang sekali mengikutsertakan karyawatinya, jika karyawati ingin berpartisipasi dalam pelatihan, maka karyawati harus membayarnya dengan uang pribadi milik karyawati. Pada dimensi partisipasi gambaran kualitas kehidupan kerja berada pada kategori dengan total persentase 53,5\%. Hal ini menunjukkan bahwa PT.K telah memberikan kesempatan bagi para karyawatinya untuk ikut serta dalam pengambilan keputusan dan juga berbagai hal lainnya yang bersangkutan dengan perusahaan. Pada dimensi lingkungan fisik gambaran kualitas kehidupan kerja berada pada kategori tinggi dengan total persentase 52,6\%. Hal ini menunjukkan bahwa PT.K telah menyediakan lingkuan fisik kerja yang cukup aman dan nyaman bagi karyawati yang bekerja di PT.K, kendala yang terjadi adalah karyawati kesulitan untuk meminta ijin pulang lebih cepat ketika terjadi kendala di rumahnya, dan karyawati yang merasa jam kerjanya terlalu padat.

Pada dimensi atasan gambaran kualitas kehidupan kerja berada pada kategori tinggi dengan total persentase $57,8 \%$. Hal ini menunjukkan bahwa interaksi yang terjalin antara atasan dan karyawati dapat terjalin dengan baik di PT.K, meliputi pemberian feedback pada hasil pekerjaan karyawati, kendala yang dirasakan oleh karyawati di PT.K adalah atasan yang tidak membantu karyawatinya dalam penyelesaian masalah yang tidak dapat ditangani oleh karyawati tersebut.

Pada dimensi gaji dan benefit gambaran kualitas kehidupan kerja berada pada kategori tinggi dengan total persentase 54,4\%. Hal ini menunjukkan bahwa karyawati yang bekerja di PT.K merasa cukup puas dengan gaji yang telah diberikan, dapat memenuhi kebutuhan hidupnya dengan gaji yang diberikan, dan juga berbagai tunjangan yang diberikan oleh PT.K. meliputi tunjangan hari raya, asuransi kesehatan, dan sebagainya.

Pada dimensi relevansi sosial gambaran kualitas kehidupan kerja berada pada kategori tinggi dengan total persentase $72,8 \%$. Hal ini menunjukkan bahwa persepsi karyawati pada PT.K cukup 
baik dan karyawati merasa bangga akan pekerjaannya di PT.K Pada dimensi integrasi sosial gambaran kualitas kehidupan kerja berada pada kategori sangat tinggi dengan total persentase kategori 92,1\%. Hal ini menunjukkan bahwa interaksi yang terjalin sesama karyawati di PT.K sangat baik, meliputi pembagian tugas yang merata, kerja sama tim yang kompak dan juga penyelesaian konflik yang terjadi antara sesama karyawati.

Hasil uji korelasi Work family conflict dengan kualitas kehidupan kerja menunjukkan adanya hubungan negatif signifikan. Hal tersebut dibuktikan dengan nilai Pearson Correlation sebesar -0,592 yang menunjukkan hubungan yang cukup kuat antara variabel Work family conflict dengan kualitas kehidupan kerja tidak searah yang merupakan bentuk korelasi negatif. Sehingga dapat ditarik kesimpulan bahwa hipotesa penelitian ditolak yang berarti terdapat hubungan antara Work family conflict dengan kualitas kehidupan kerja pada karyawati yang telah menikah di PT.K.

\section{DISKUSI}

Berdasarkan hasil penelitian Work family conflict memiliki hubungan yang cukup kuat dengan kualitas kehidupan kerja karyawati, hal ini diperkuat dengan pernyataan Greenhaus dan Beutell (dalam Etikarina, 2011) dimana Work family conflict seringkali dihubungkan dengan ketidakpuasan dan kesulitan individu untuk dapat menyeimbangkan peran dalam pekerjaan maupun dalam keluarga. Oleh karenanya, perusahaan diharapkan dapat menyediakan fasilitas bagi karyawati dalam rangka untuk dapat membantu para karyawati untuk dapat menyeimbangkan perannya di kedua domain tersebut. Jika perusahaan dapat menciptakan lingkungan kerja dengan kualitas kehidupan kerja yang baik, maka diharapkan dapat membantu karyawatinya untuk mengatasi Work family conflict yang dimilikinya. Jika karyawati dapat mengatasi Work family conflict yang dimilikinya, maka dapat meningkatkan performa sehingga perusahaan dapat memiliki sumber daya manusia yang berkualitas. 
Berdasarkan hasil penelitian Work family conflict memiliki hubungan yang cukup kuat dengan kualitas kehidupan kerja karyawati, hal ini diperkuat dengan pernyataan Greenhaus dan Beutell (dalam Etikarina, 2011) dimana Work family conflict seringkali dihubungkan dengan ketidakpuasan dan kesulitan individu untuk dapat menyeimbangkan peran dalam pekerjaan maupun dalam keluarga. Oleh karenanya, perusahaan diharapkan dapat menyediakan fasilitas bagi karyawati dalam rangka untuk dapat membantu para karyawati untuk dapat menyeimbangkan perannya di kedua domain tersebut.

\section{KESIMPULAN DAN SARAN}

Berdasarkan penelitian yang dilakukan, peneliti mendapatkan hasil bahwa terdapat karyawati yang telah menikah dan bekerja di PT.K memiliki gambaran Work family conflict yang cenderung tinggi dengan persentase dalam kategori tinggi (28,1\%) dan sangat tinggi (26,3\%), sehingga dapat disimpulkan total persentase dari Work family conflictcenderung tinggi yaitu 54,4\%. Dari hasil perhitungan norma diperoleh dimensi Work family conflict cenderung tinggi yaitu dengan dimensi time based conflict $(57,1 \%)$, strain based conflict $(61,4 \%)$, dan behavior based conflict $(50,9 \%)$. Mengenai kualitas kehidupan kerja, karyawan PT.K memiliki gambaran kualitas kehidupan kerja yang cenderung tinggi. Hal ini dibuktikan dengan persentase kualitas kehidupan kerja sebesar 50,9\% dengan kategori tinggi (24,6\%) dan sangat tinggi (26,3\%). Dari hasil perhitungan norma diperoleh dimensi kualitas kehidupan kerja yang tinggi adalah pertumbuhan dan pengembangan $(72,8 \%)$, partisipasi (53,5\%), lingkungan fisik (52,6\%), atasan $(57,8 \%)$, gaji dan benefit $(54,4 \%)$, relevansi sosial (72,8\%). Sedangkan yang berada dalam kategori sangat tinggi adalah dimensi integrasi sosial $(82,1 \%)$ 
Penelitian ini menunjukkan adanya hubungan antara Work family conflict dengan kualitas kehidupan kerja pada karyawati yang telah menikah dan bekerja di PT.K dengan nilai pearson correlation sebesar -0,592. Pada dimensi Work family conflict menunjukkan adanya korelasi dengan kualitas kehidupan yang cukup kuat. Seperti dimensi time based conflict dengan kualitas kehidupan kerja $(r=0,527)$, strain based conflict dengan kualitas kehidupan kerja $(r=0,514)$, dan behavior based conflict dengan kualitas kehidupan kerja $(r=0,590)$.

Saran untuk penelitian selanjutnya adalah diharapkan peneliti dapat melakukan penelitian dapat dilakukan dengan penelitian yang lebih banyak, dan penambahan item kuesioner dengan menggunakan open ended question, dengan ditambahkannya open ended question, diharapkan dapat membantu peneliti untuk melihat hasil penelitian lebih dalam.

\section{DAFTAR PUSTAKA}

Aamodt, M.G. (2007). Industrial Organizational Psychology. USA: Wadsworth Cangage Learning Almasitoh, U. H. (2011). Stress kerja ditinjau dari konflik peran ganda dan dukungan sosial pada perawat. Jurnal Psikologi Islam. Retrieved from http://psikologi.uin-malang.ac.id/wpcontent/uploads/2014/03/

Arikunto, S. (2010). Prosedur Penelitian: Suatu Pendekatan Praktik Edisi Revisi 2010. Jakarta: Rineka Cipta

Ashar, A (2016). Hubungan Work family conflict dengan Quality of Work Life pada Karyawan Wanita Swasta. Jurnal Ilmiah Psikologi, 9(2), 121-131.

Buhali, G. A., \& Margaretha, M. (2013). Pengaruh Work-Family Conflict terhadap Komitmen Organisasi: Kepuasan Kerja sebagai Variabel Mediasi. Jurnal Manajemen, 13(1), 14-33.

Christine W.S (2010). Pengaruh Konflik Pekerjaan dan Konflik Keluarga Terhadap Kinerja dengan Konflik Pekerjaan Keluarga Sebagai Intervening Variabel (Studi pada Dual Career Couple di Jabodetabek). Jurnal Manajemen dan Kewirausahaan, 2(2), 121-132.

Chusniatun, Kuswardhani, \& Suwandi, J. (2014). Peran ganda dan pengembangan karier guru - guru perempuan di sekolah muhammadiyah di Kota Surakarta, Jurnal Pendidikan Ilmu Sosial, 24(2), 53-66. Retrieved from http://journals.ums.ac.id/index.php/jpis/article/view/689

Considine, G., \& Callus, R. (2001). The Quality of Work Life of Australian Employee. Retrieved from http://www.google.com/quality+working+of+life 
Cohen, R.J. \& Swerdlik, M.E. (2010). Psychological Testing and Assessment. New York: McGrawHill

Irawati, A.S. (2015). Pengaruh Kualitas Kerja terhadap Kinerja Pegawai Dinas Perindustrian dan Perdagangan Kabupaten Sampang. Jurnal Neo-Bis, 9(2), 41-52

Laksmi, N. A. P., \& Hadi, C. (2012). Hubungan antara Konflik Peran Ganda (Work Fammily Conflict) dengan Kepuasan Kerja pada Karyawati bagian Produksi PT. X. Jurnal Psikologi Industri dan Organisasi, 1(2), 124- 130.

Muharnis, S., Etikaerina, A., \& Yulianto, A. (2011). Hubungan Konflik Kerja- Keluarga dengan Kualitas Kehidupan Kerja pada Karyawati Bank. Journal of Pscyhology TAZKIYA, 14, 252263.

Tsai, H.Y. (2008). Work family conflict, positive spillover, and emotions among Asian American working mothers (Doctoral dissertation). Retrieved from https://deepblue.lib.umich.edu/bitstream/handle/2027.42/60855/athy_1.pdf?sequence=1\&isAllo wed $=\mathrm{y}$

Winarto, Y. (2018). BPS: Jumlah angkatan kerja Agustus naik 2.95 juta. Retrieved https://nasional.kontan.co.id/news/bps-jumlah-angkatan-kerja-agustus-naik-295-juta

Zin, R. M. (2004). Perception of professional engineers toward quality of worklife and organizational commitment: A case study. Gadjah Mada International Journal of Business, 6(3), 323-33 